\title{
FOSSIL BEETLE ELYTRA
}

\author{
By T. D. A. COCKerell \\ Boulder, Colorado
}

Mr. Darlington's remarks in the September Psyche suggest that it may be useful to make a further statement as follows :

(1.) Beetle elytra are of value for stratigraphy, because they are present in many different rocks, and often in considerable numbers. The faunæ are recognizable if well figured, and the species are not too few.

(2.) Fossil elytra are also of value as showing the amount of diversification of these structures in different periods, and especially the antiquity of various characters or structures.

These two reasons seem to me to justify the description and naming of fossil elytra.

(3.) On the other hand, in the majority of cases it is impossible to refer the elytra to definite genera, or in some instances to definite families. Thus a species may be recognizable though its generic position is unknown. In all such cases it seems best to use "blanket-genera," such as Carabites, rather than to refer the species to numerous supposedly extinct genera, which cannot be accurately defined.

(4.) It is however probable that when students intensively investigate the elytral structures of modern beetles, many more good generic characters will be found than are now known to exist. If so, it may be possible to return to the fossils, and feel some assurance of their correct position.

\section{PARATENETUS CRINITUS FALL}

Sherborn, Mass., has furnished another surprise, or rather several of them, in five or six specimens of what appears to be the above species which was described from New Mexico. At least three of the specimens were taken by sifting. The dates of capture are:-May 11, 1913; May 2, 

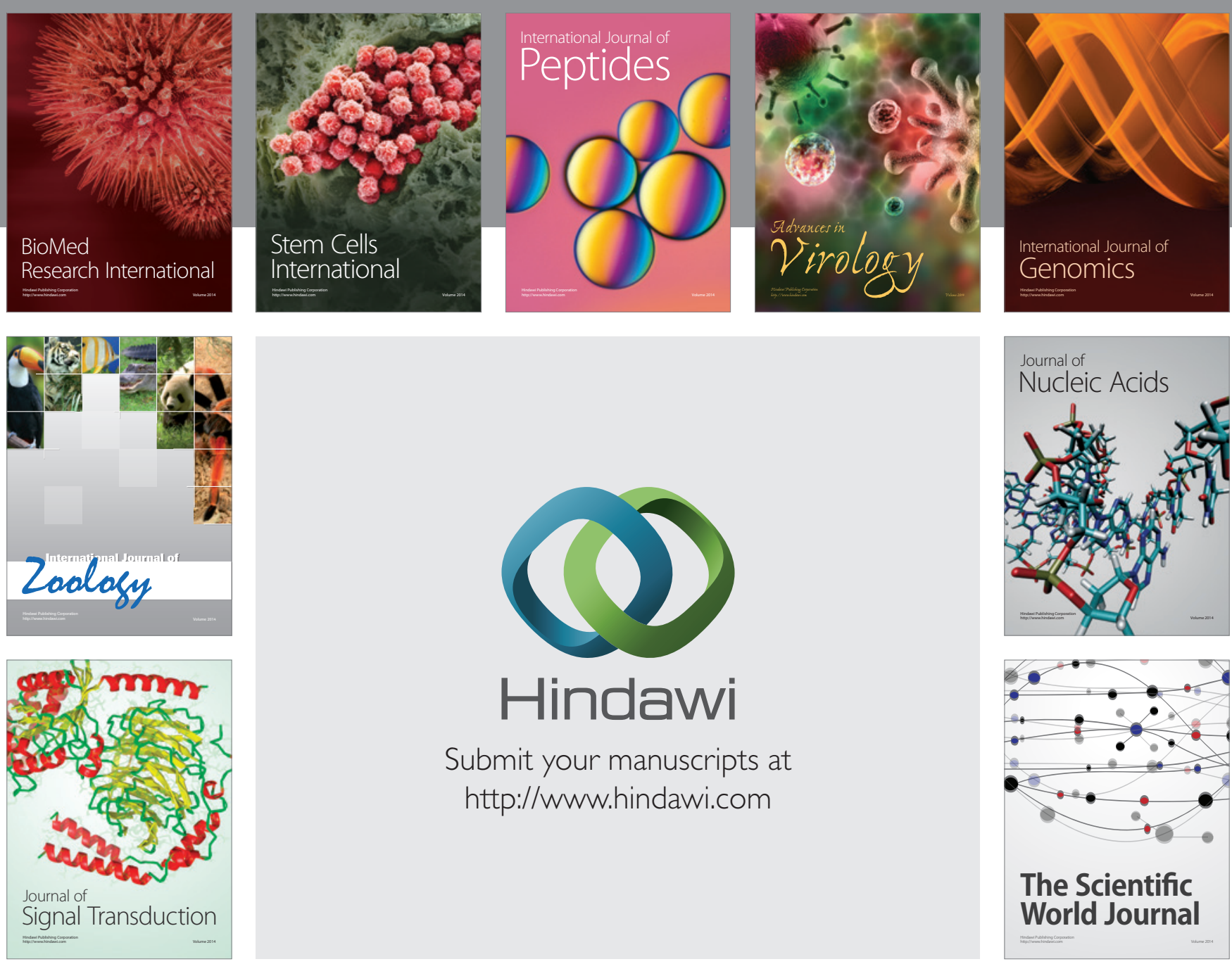

Submit your manuscripts at

http://www.hindawi.com
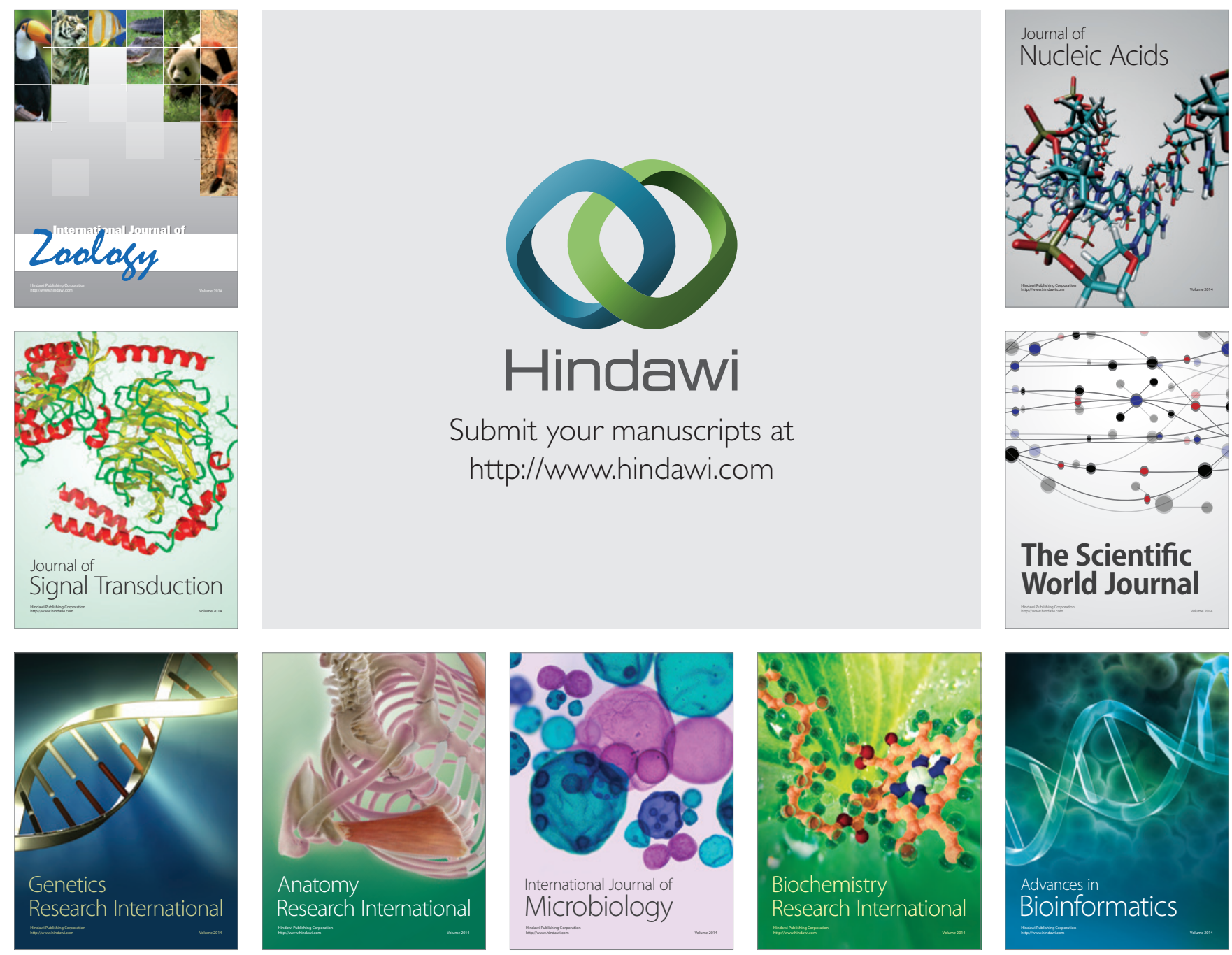

The Scientific World Journal
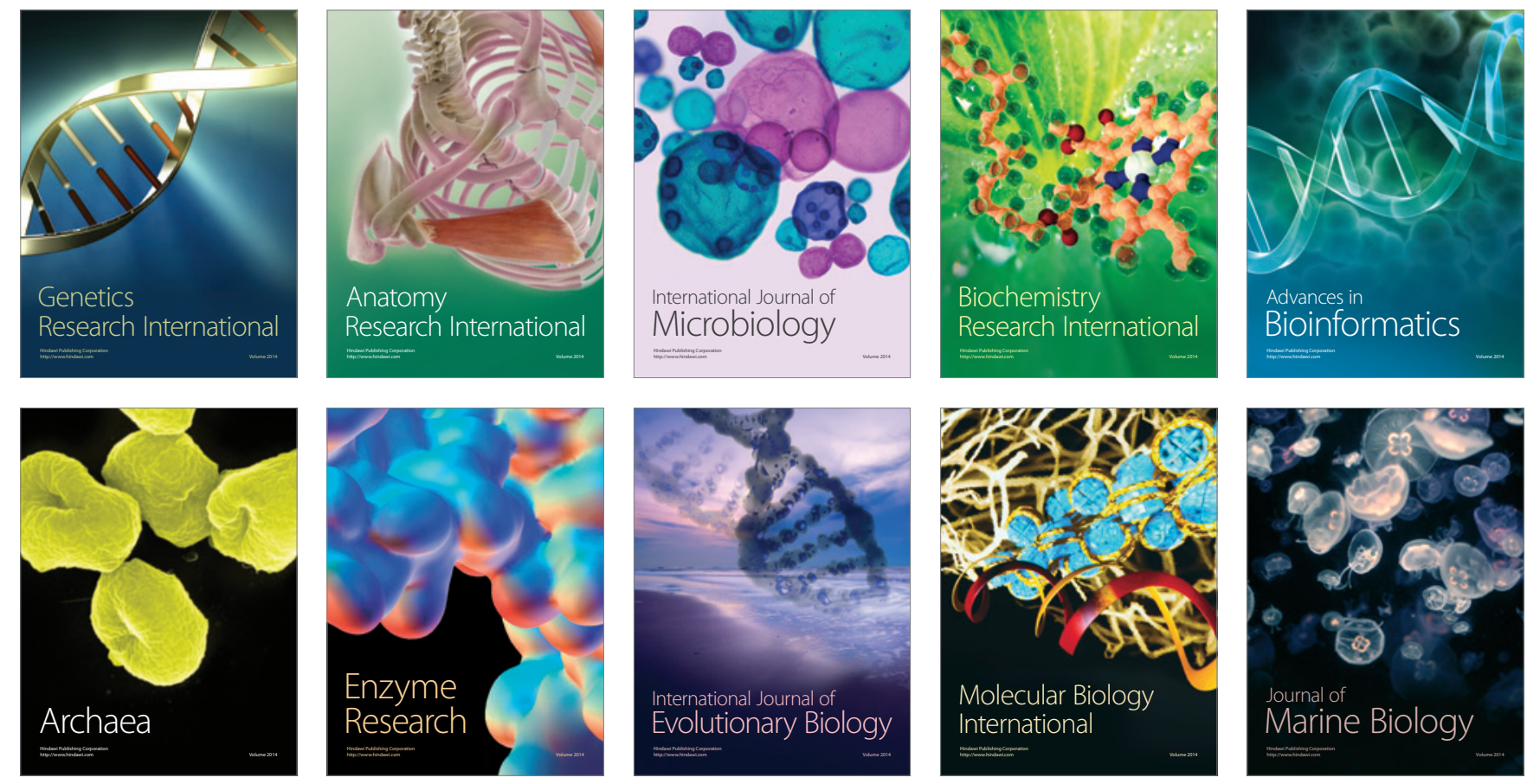